\title{
Investigation of antimicrobial susceptibility, class I and II integrons among Pseudomonas aeruginosa isolates from hospitalized patients in Isfahan, Iran
}

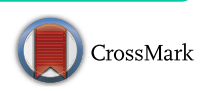

\author{
Jamshid Faghri ${ }^{1}$, Samereh Nouri ${ }^{2}$, Saba Jalalifar ${ }^{1}$, Mehrdad Zalipoor ${ }^{1}$ and Mehrdad Halaji ${ }^{3^{*}}$
}

\begin{abstract}
Objectives: The role of integrons in the transfer of antibiotic resistance is one of the important issues, therefore, this study is aimed to investigate antibiotic resistance pattern and prevalence of class 1 and 2 integrons in $P$. aeruginosa isolated.

Results: Out of 72 confirmed $P$. aeruginosa isolates, $50 \%$ were from ICU patients. Antibacterial susceptibility pattern showed that isolates were most resistant to ceftazidime (76.4\%) and colistin was the most effective antibiotic (100\%) and molecular analysis of class I and II integrons showed $55.5 \%$ and $29.1 \%$ of isolates were positive, respectively and the proportions of MDR isolates were significantly higher among integron-positive isolates with $73.6 \%$ compared to negative isolates with 22.9\%. Our results showed that there was a correlation among class 1 and 2 integrons with MDR P. aeruginosa isolates. According to the importance of integrons in acquisition and dissemination of antibiotics resistance genes, the performance of antibiotic surveillance programs and investigating the role of integrons is recommended to control the spreading of antibiotics resistance genes.
\end{abstract}

Keywords: Pseudomonas aeruginosa, Antibiotic resistance, Integrons

\section{Introduction}

Pseudomonas aeruginosa is a non-fermenting aerobic Gram-negative bacillus known as a significant pathogen leading to severe infections in hospitals and rarely causes infection in the natural host [1]. P. aeruginosa is an important opportunistic pathogen leading to severe infections in patients with cystic fibrosis, neutropenia, iatrogenic immunosuppression, or severe burns [2, 3]. The increasing use of antibiotics is likely the main reason for the evolution of multidrug-resistant (MDR) P. aeruginosa outbreaks in clinical settings $[4,5]$. Generally, bacterial resistance can be explained by either the mutation of genes or exchangeable genetic elements such as plasmids,

\footnotetext{
*Correspondence: m.hallaji@resident.mui.ac.ir; mehrdad.md69@gmail. com

${ }^{3}$ Students Research Committee, Isfahan University of Medical Sciences, Hezar Jarib St, Isfahan, Iran

Full list of author information is available at the end of the article
}

transposons, and integrons [6]. Integrons are transportable genetic elements which can transfer the antibiotic resistance genes. These elements can be placed in different parts of plasmids and chromosomes. Integrons are able to capture external drug resistance gene cassettes and incorporate them using site-specific recombination. It is potentially a major agent in the rapid spread of resistance in bacteria, especially among the Gram-negative [6]. The overall structure of integrons includes an integrase gene, two stable conservative reigns called sull and int 1 as well as a variable region of gene cassettes between the two conserved segments [7]. According to the integrase gene, four classes of integrons have been described in Gram-negative organisms, however, class 1 integrons have been described to be the most prevalent in clinical isolates, carrying single or several gene cassettes, which confer resistance to a wide range of antibiotics such as $\beta$-lactams, fluoroquinolones, aminoglycosides, 
chloramphenicol, erythromycin, antiseptics, and disinfectants [7]. The second class of integrons (class 2) is commonly found to be associated with the Tn7 transposon family and it contains integrase gene (intI2), one recombinant location (aatI 2) and a cassette gene without SulI in its $3^{\prime}$ terminal region. Class 2 integrons have been reported in some species of Gram-negative bacteria such as Acinetobacter, Enterobacteriaceae, Salmonella and Pseudomonas [8]. Compared with class 2 integron, class 3 integron contains a similar structure and this class of integrin have been described as rare and found only within a few microorganisms such as Serratia marcescens, Klebsiella pneumoniae and P. aeruginosa [8-10]. Furthermore, class 4 integron which harbor a wide range of gene cassettes encoding antibiotic resistance and pathogenicity was firstly identified on the small chromosome of Vibrio cholerae [8].

Regarding the significant role of $P$. aeruginosa in nosocomial infections and also the role of integrons in the dissemination of antibiotic resistance, this study is aimed to evaluate the frequency of class 1 and 2 integrons in $P$. aeruginosa isolates of nosocomial infection in order to determine the antibiotic resistance pattern of this bacterium.

\section{Main text \\ Methods}

A cross-sectional study was performed during the period April 2016 to August 2016 at a teaching hospital affiliated to Isfahan University of Medical Sciences, Isfahan, Iran. The non-replicated $P$. aeruginosa isolates were obtained from various clinical specimens such as blood, wounds, urine and other samples and transported to the laboratory for further analysis. The specimens were cultured on blood agar and MacConkey's agar (Merck, Germany) and incubated overnight at $37{ }^{\circ} \mathrm{C}$. Bacterial isolates were identified as $P$. aeruginosa using standard microbiological methods, including Gram staining, production of acid from different sugars, catalase, oxidase, motility, and genotypic method (the presence of the tox- $A$ gene). The confirmed isolates were stored at $-80{ }^{\circ} \mathrm{C}$ in brain heart infusion (BHI) broth containing 20\% glycerol [11, 12].

Antibiotic susceptibility was performed based on disk diffusion method on Mueller-Hinton agar (Himedia, India) according to the Clinical and Laboratory Standards Institute (CLSI) recommendation for meropenem $(10 \mu \mathrm{g})$, cefepime $(30 \mu \mathrm{g})$, ceftazidime $(30 \mu \mathrm{g})$, piperacillin-tazobactam $(100 / 10 \mu \mathrm{g})$, colistin-sulfate $(10 \mu \mathrm{g})$, amikacin $(30 \mu \mathrm{g})$, ciprofloxacin $(5 \mu \mathrm{g})$ and levofloxacin $(\mu \mathrm{g})$; disks (MAST, Merseyside, UK). P. aeruginosa ATCC 27853 was also tested as the control positive. However, multi-drug resistant isolates were defined as those resistant to at least three of antibiotics classes [13].
A simple boiling method was used to extract genomic DNA from $P$. aeruginosa isolates as described previously [14]. The polymerase chain reaction (PCR) was carried out to detect the tox- $A$ gene and the presence of class 1 and 2 integrons cassette using the specific primers [15].

PCR amplification consisted of a pre-denaturation step at $94{ }^{\circ} \mathrm{C}$ for $5 \mathrm{~min}$, followed by 35 cycles of denaturation at $94{ }^{\circ} \mathrm{C}$ for $45 \mathrm{~s}$, primer annealing at $54{ }^{\circ} \mathrm{C}$ for intI1 and intI2 and extension at $72{ }^{\circ} \mathrm{C}$ for $60 \mathrm{~s}$, and a final extension at $72{ }^{\circ} \mathrm{C}$ for $7 \mathrm{~min}$. The PCR products were analyzed on agarose gel with KBC power load dye (CinnaGen Co. Iran) and finally visualized in gel documentation system. Positive results were confirmed by direct sequencing of the PCR products.

SPSS Statistics (IBM Corp. Released 2012. IBM SPSS Statistics for Windows, Version 21.0. Armonk, NY: IBM Corp.) was used for statistical analysis. Chi square or Fisher's exact test was used to determine any statistical association. Statistical significance was regarded as $p$-values $<0.05$. The results are showed using descriptive statistics in terms of relative frequency.

\section{Results}

A total of 72 confirmed $P$. aeruginosa isolates were obtained from various clinical samples of a selected teaching hospital in Isfahan, Iran. Totally, 66.7\% (48/72) P. aeruginosa isolates were obtained from male and $33.3 \%$ (24/72) from female hospitalized patients. The distribution of $P$. aeruginosa isolates in different hospital wards and clinical specimens showed that half of the isolates were collected from ICU and most of the isolates were isolated from trachea samples. Table 1 shows the distribution of clinical specimens and different wards based on integron-positive $P$. aeruginosa isolates.

Antibacterial susceptibility pattern showed a high rate of antibiotic resistance to ceftazidime $76.4 \%$ followed by ciprofloxacin $73.6 \%$. However, all of the isolates were susceptible to colistin (100\%) and the lowest antibiotic resistance rates were seen against amikacin (41.6\%) followed by piperacillin/tazobactam (48.6\%).

PCR amplification of the two class 1 and 2 integrons cassette showed that $55.5 \%$ and $29.1 \%$ of isolates were positive for class 1 and 2 integrons, respectively.

The high level of resistance in class 1 and 2 integronpositive isolates were seen to ceftazidime (82.5) and ciprofloxacin $(76.2 \%)$, respectively, whereas amikacin and piperacillin/tazobactam were the most effective antibiotics to integron-positive isolates. The full antibiotic resistance pattern of the integron-positive and integronnegative isolates are presented in Tables 2 and 3. According to our results, a significant correlation between the presences of class I integron and a higher rate of resistance related to meropenem was seen $(p$-value $<0.001)$. 
Table 1 Frequency of integron-positive $P$. aeruginosa isolates based on clinical specimens and different wards

\begin{tabular}{llll}
\hline Wards & Integron-1 positive no. $\mathbf{( \% )}=\mathbf{4 0}$ & Integron-2 positive no. (\%) $\mathbf{2 1}$ & Total no.=61 \\
\hline ICU & $23(57.5)$ & $11(52.4)$ & 34 \\
Emergency & $7(17.5)$ & $4(19)$ & 11 \\
Surgery & $5(12.5)$ & $2(9.5)$ & 7 \\
Internal medicine & $3(7.5)$ & $1(4.8)$ & 4 \\
Others & $2(5)$ & $3(14.3)$ & 5 \\
\hline Clinical sample & Integron-1 positive no. (\%) & Integron-2 positive no. (\%) & Total no.=61 \\
\hline Trachea & $18(45)$ & $9(43)$ & 27 \\
Urine & $9(22.5)$ & $5(23.7)$ & 2 \\
CSF & $2(5)$ & - & 8 \\
Wound & $5(12.5)$ & $3(14.3)$ & 14 \\
Others & $6(15)$ & $4(19)$ & 10 \\
MDR & $32 / 40$ & $15 / 21$ & $53(73.5)$ \\
\hline
\end{tabular}

Table 2 Antibiotic susceptibility pattern of class 1 integron-positive and integron-negative of $P$. aeruginosa strains

\begin{tabular}{llll}
\hline Antibiotics & $\begin{array}{l}\text { Integron-1 positive } \\
\mathbf{n = 4 0} \\
\text { No. }(\%)\end{array}$ & $\begin{array}{l}\text { Integron-1 } \\
\text { negative } \\
\mathbf{n = 3 2} \\
\text { No. }(\%)\end{array}$ & $p$-value \\
\hline Meropenem & $30(75)$ & $13(40.5)$ & 0.003 \\
Cefepime & $31(77.5)$ & $21(65.6)$ & 0.2 \\
Ceftazidime & $33(82.5)$ & $22(69)$ & 0.17 \\
Piperacillin/tazobactam & $23(57.5)$ & $12(37.5)$ & 0.09 \\
Ciprofloxacin & $31(77.5)$ & $22(69)$ & 0.4 \\
Levofloxacin & $30(75)$ & $21(65.6)$ & 0.38 \\
Amikacin & $19(47.5)$ & $11(34.4)$ & 0.36 \\
Colistin & 0 & 0 & -
\end{tabular}

Table 3 Antibiotic susceptibility pattern of class 2 integron-positive and integron-negative of $P$. aeruginosa strains

\begin{tabular}{llll}
\hline Antibiotics & $\begin{array}{l}\text { Integron-1 positive } \\
\mathbf{n = 4 0} \\
\text { No. }(\%)\end{array}$ & $\begin{array}{l}\text { Integron-1 } \\
\text { negative } \\
\mathbf{n = 3 2} \\
\text { No. (\%) }\end{array}$ & p-value \\
\hline Meropenem & $30(75)$ & $13(40.5)$ & 0.003 \\
Cefepime & $31(77.5)$ & $21(65.6)$ & 0.2 \\
Ceftazidime & $33(82.5)$ & $22(69)$ & 0.17 \\
Piperacillin/tazobactam & $23(57.5)$ & $12(37.5)$ & 0.09 \\
Ciprofloxacin & $31(77.5)$ & $22(69)$ & 0.4 \\
Levofloxacin & $30(75)$ & $21(65.6)$ & 0.38 \\
Amikacin & $19(47.5)$ & $11(34.4)$ & 0.36 \\
Colistin & 0 & 0 & - \\
\hline
\end{tabular}

The rate of MDR phenotype among integron-positive isolates $(73.6 \% ; n=53)$ were significantly higher in compared to integron-negative isolates with $22.9 \%(n=16)$.

\section{Discussion}

Pseudomonas aeruginosa is one of the most important pathogen causing a wide range of infections in the hospitals and healthcare settings [16]. The spread of resistance to antimicrobial agents and the emergence of clinical multidrug resistance $P$. aeruginosa isolates in clinical settings has become a serious problem in the treatment of nosocomial infections worldwide $[17,18]$. Resistance to antimicrobial agents can be originated from many resistance genes that present as gene cassettes and transferred through integrons which are located on transmissible plasmids, the chromosome, and transposons [10]. In the present study, based on antibiotic susceptibility pattern, colistin was the most effective antibiotic agent with the susceptibility rate of $100 \%$, while most of $P$. aeruginosa isolates showed high resistance rate to antimicrobial agents. In accordance to our results, Khosravi et al. from south of Iran, Mobaraki et al. and Goli et al. from Northwest of Iran, reported that colistin was the most effective and the drug of choice in the management of nosocomial infection [19-21].

In another study carried out by Fazeli et al. [22] in our region, lower resistance rate was described for quinolones and cephems agents. Among them, a resistance rate of $63 \%$ and $63.1 \%$ were reported for both ciprofloxacin and ceftazidime, respectively. Whereas, our results showed a higher resistance to quinolones and cephems groups especially ciprofloxacin and ceftazidime which demonstrated an increasing trend of this resistance in hospitalized patients in Isfahan. In our finding, the rate 
of resistance to amikacin was $41 \%$ that was lower than reports from the south of Iran and were also reported in other parts of the world [19, 21-24]. To our knowledge, this is the first study addressing the investigation of a different class of integron in $P$. aeruginosa isolates in our region, therefore, this present study demonstrated the importance and frequency of classes 1 and 2 integrons and the importance of them in relation to high antibiotic resistance $P$. aeruginosa isolates.

In the present study, $55.5 \%$ and $29 \%$ of $P$. aeruginosa isolates were contained class 1 and 2 integrons, meanwhile, $16.6 \%$ of isolates carried both classes of integron genes, simultaneously.

The overall data show that the prevalence of int 1 gene in clinical isolates was closest to most of the previous investigations from Iranian studies ranging from 27.5 to $66 \%$ and the results of studies conducted in other countries [20, 21, 25-28].

The emergence of the high frequency of intI1 in our region may explain a serious concern in the future and can cause an increase and dissemination of antibiotic resistance that is related to the presence of class 1 integron. In similar studies from Iran, due to inappropriate use of antibiotics, the origin of infections and geographical distribution, the prevalence of class 2 gene in clinical isolates of $P$. aeruginosa is variable. Accordingly, in contrast to our finding, other studies have reported a variable frequency of class 2 integrons among clinical $P$. aeruginosa. Khosravi et al., Hosseini Pour et al. from Ahvaz city and Mobaraki et al. from Northwestern Iran showed $0 \%, 52 \%$ and $25.5 \%$ isolates harboring class 2 integrons, respectively $[19,21,29]$.

According to the previous finding, there is an association between the presence of multiple resistance and different classes of Integron, especially class 1 integrons [30]. Bearing in mind our results, in compared to negative isolates, the proportion of MDR isolates among integron-positive isolates were considerably higher, which can confirm the importance of these elements in the spreading of resistance genes among pathogens.

In agreement with our findings, a high rate of MDR isolates among integron-positive were reported by Ebrahimpour et al. [31]. Moreover, Khosravi et al. [19] also showed there is a correlation between the presence of class 1 integrons and MDR isolate and high antimicrobial resistance especially for gentamicin (94.62\%), ciprofloxacin (93.54\%), and meropenem (90.32\%).

Although the resistance rate of meropenem was significantly differenced in class 1 integron-positive than in integron negative isolates, there was no significant correlation between most antibiotics used and integron-positive isolates in our study. Therefore, the use of inappropriate antibiotics, selective pressure, and other factors may be considered for high resistance to antibiotics. The results of our finding describe the importance of class 1 and 2 integrons in multiple antibiotic resistance and its association with MDR $P$. aeruginosa isolates. Therefore, integrons play an important role in acquisition and dissemination of antibiotics resistance genes among these pathogens, so, management of infection control policies and the appropriate use of antibiotics is necessary for control the spreading of antibiotics resistance genes.

\section{Limitations}

The lack of investigation and characterization of resistance gene cassettes associated with class 1 and 2 integrons can be mentioned as one of the main limitations of the present study.

\section{Abbreviations \\ aatl 2: recombinant location; BHI: brain heart infusion; CLSI: Clinical and Laboratory Standards Institute; intl2: integrase gene; PCR: polymerase chain reaction; MDR: multidrug-resistant.}

\section{Authors' contributions}

$\mathrm{MH}, \mathrm{JF}$ : conceived, designed and supervised the study and revised the manuscript; SJ, SN, and MZ: collected and analyzed the data and drafted the manuscript. All authors read and approved the final manuscript.

\section{Author details}

${ }^{1}$ Department of Microbiology, School of Medicine, Isfahan University of Medical Sciences, Isfahan, Iran. ${ }^{2}$ Department of Microbiology, Clinical Laboratory of ALZAHRA Medical Center, Isfahan, Iran. ${ }^{3}$ Students Research Committee, Isfahan University of Medical Sciences, Hezar Jarib St, Isfahan, Iran.

\section{Acknowledgements}

We are thankful to all Members of the Department of Microbiology, School of Medicine, and Isfahan University of Medical Sciences.

\section{Competing interests}

The authors declare that they have no competing interests.

\section{Availability of data and materials}

The datasets used and/or analyzed during the current study are available from the corresponding author on reasonable request.

\section{Consent for publication}

Not applicable.

\section{Ethics approval and consent to participate}

The study protocol was approved by the Ethics Committee of Isfahan University of Medical Sciences (IR.MUI.REC.1395.1.167), however, we did not have human participants. The study used bacteria isolated from clinical samples in the clinical microbiology laboratory.

\section{Funding}

This study was supported by Students Research Committee, Isfahan University of Medical Sciences, and Isfahan, Iran (Grant No 195167).

\section{Publisher's Note}

Springer Nature remains neutral with regard to jurisdictional claims in published maps and institutional affiliations. 
Received: 7 August 2018 Accepted: 1 November 2018

Published online: 12 November 2018

\section{References}

1. Sadikot RT, Blackwell TS, Christman JW, Prince AS. Pathogen-host interactions in Pseudomonas aeruginosa pneumonia. Am J Respir Crit Care Med. 2005;171:1209-23.

2. Goldberg JB. Why is Pseudomonas aeruginosa a pathogen? F1000 Biol Rep. 2010;2:29.

3. Rada B. Interactions between neutrophils and Pseudomonas aeruginosa in cystic fibrosis. Pathogens. 2017:6:10.

4. Hirsch EB. Impact of multidrug-resistant Pseudomonas aeruginosa infection on patient outcomes. Expert Rev Pharmacoecon Outcomes Res. 2010;10:441-51.

5. Aloush V, Navon-Venezia S, Seigman-Igra Y, Cabili S, Carmeli Y. Multidrugresistant Pseudomonas aeruginosa: risk factors and clinical impact. Antimicrob Agents Chemother. 2006;50:43-8.

6. Bennett PM. Plasmid encoded antibiotic resistance: acquisition and transfer of antibiotic resistance genes in bacteria. Br J Pharmacol. 2008;153:S347-57.

7. Gillings MR. Integrons: past, present, and future. Microbiol Mol Biol Rev. 2014:78:257-77

8. Deng Y, Bao X, Ji L, Chen L, Liu J, Miao J, et al. Resistance integrons: class 1, 2 and 3 integrons. Ann Clin Microbiol Antimicrob. 2015;14:45.

9. Hansson K, Sundström L, Pelletier A, Roy PH. Intl2 integron integrase in Tn7. J Bacteriol. 2002;184:1712-21.

10. Hall RM, Collis CM. Antibiotic resistance in gram-negative bacteria: the role of gene cassettes and integrons. Drug Resist Updates. 1998;1:109-19.

11. Mahon CR, Mahon R. Textbook of diagnostic microbiology. Moorpark: Content Technologies, Inc; 2015.

12. Pillar CM, Hobden JA. Pseudomonas aeruginosa exotoxin A and keratitis in mice. Invest Ophthalmol Vis Sci. 2002;43:1437-44.

13. Wayne P. Clinical and Laboratory Standards Institute: performance standards for antimicrobial susceptibility testing: twenty-fourth informational supplement, M100-S24. Clinical and Laboratory Standards Institute (CLSI). 2014;34.

14. Halaji M, Karimi A, Shoaei P, Nahaei M, Khorvash F, Ataei B, et al. Distribution of SCCmec elements and presence of panton-valentine leukocidin in methicillin-resistant Staphylococcus. J Clin Diagn Res. 2017;11:DC27-31.

15. Machado E, Canton R, Baquero F, Galan JC, Rollan A, Peixe L, et al. Integron content of extended-spectrum-beta-lactamase-producing Escherichia coli strains over 12 years in a single hospital in Madrid, Spain. Antimicrob Agents Chemother. 2005;49:1823-9.

16. Gellatly SL, Hancock RE. Pseudomonas aeruginosa: new insights into pathogenesis and host defenses. Pathog Dis. 2013;67:159-73.

17. Biswal I, Arora BS, Kasana DN. Incidence of multidrug resistant Pseudomonas aeruginosa isolated from burn patients and environment of teaching institution. J Clin Diagn Res. 2014;8:DC26-9.
18. van Duin D, Paterson D. Multidrug resistant bacteria in the community: trends and lessons learned. Infect Dis Clin North Am. 2016;30:377-90.

19. Khosravi AD, Motahar M. The frequency of class 1 and 2 integrons in Pseudomonas aeruginosa strains isolated from burn patients in a burn center of Ahvaz, Iran. PLoS ONE. 2017;12:e0183061.

20. Goli HR, Nahaei MR, Rezaee MA, Hasani A, Kafil HS, Aghazadeh M, et al. Prevalence and molecular characterization of class 1 integrons among clinical isolates of Pseudomonas aeruginosa in Northwest of Iran. Mol Genet Microbiol Virol. 2017;32:109-15.

21. Mobaraki S, Aghazadeh M, Barhaghi MHS, Memar MY, Goli HR, Gholizadeh $P$, et al. Prevalence of integrons 1, 2, 3 associated with antibiotic resistance in Pseudomonas aeruginosa isolates from Northwest of Iran. Biomedicine. 2018. https://doi.org/10.1051/bmdcn/2018080102.

22. Fazeli H, Solgi $H$, Havaei SA, Shokri D, Norouzi Barogh M, Zamani FZ. Carbapenem and fluoroquinolone resistance in multidrug resistant Pseudomonas aeruginosa isolates from Al-Zahra Hospital, Isfahan, Iran. J Med Microbiol Infect Dis. 2014;2:147-52.

23. Nikokar I, Tishayar A, Flakiyan Z, Alijani K, Rehana-Banisaeed S, Hossinpour $\mathrm{M}$, et al. Antibiotic resistance and frequency of class 1 integrons among Pseudomonas aeruginosa, isolated from burn patients in Guilan, Iran. Iran J Microbiol. 2013;5:36

24. Poonsuk K, Tribuddharat C, Chuanchuen R. Class 1 integrons in Pseudomonas aeruginosa and Acinetobacter baumannii isolated from clinical isolates. Southeast Asian J Trop Med Public Health. 2012;43:376-84.

25. Halaji M, Rezaei A, Zalipoor M, Faghri J. Investigation of class I, II, and III integrons among Acinetobacter Baumannii isolates from hospitalized patients in Isfahan, Iran. Oman Med J. 2018:33:37-42.

26. Sun G, Yi M, Shao C, Ma J, Zhang Q, Shao S. Novel class 1 integrons in multi-drug resistant isolates from Eastern China. Indian J Microbiol. 2014;54:227-31.

27. Gu B, Tong M, Zhao W, Liu G, Ning M, Pan S, et al. Prevalence and characterization of class I integrons among Pseudomonas aeruginosa and Acinetobacter baumannii isolates from patients in Nanjing, China. J Clin Microbiol. 2007:45:241-3.

28. Xu Z, Li L, Shirtliff ME, Alam MJ, Yamasaki S, Shi L. Occurrence and characteristics of class 1 and 2 integrons in Pseudomonas aeruginosa isolates from patients in Southern China. J Clin Microbiol. 2009;47:230-4.

29. Hosseini Pour P, Momtaz H, Serajyan AA, Tajbakhsh E. Investigating class I, II and III integrons in multidrug resistance in Pseudomonas aeruginosa isolated from hospital infections in Ahvaz. Int J Med Lab. 2015;2:168-76.

30. Fluit AC, Schmitz FJ. Resistance integrons and super-integrons. Clin Microbiol Infect. 2004:10:272-88.

31. Ebrahimpour M, Nikokar I, Ghasemi Y, Ebrahim-Saraie HS, Araghian A, Farahbakhsh M, et al. Antibiotic resistance and frequency of class 1 integrons among Pseudomonas aeruginosa isolates obtained from wastewaters of a burn center in Northern Iran. Ann Ig. 2018;30:112-9.

Ready to submit your research? Choose BMC and benefit from

- fast, convenient online submission

- thorough peer review by experienced researchers in your field

- rapid publication on acceptance

- support for research data, including large and complex data types

- gold Open Access which fosters wider collaboration and increased citations

- maximum visibility for your research: over $100 \mathrm{M}$ website views per year

At BMC, research is always in progress.

Learn more biomedcentral.com/submissions 